\title{
Induced fit of the peptidyl-transferase center of the ribosome and conformational freedom of the esterified amino acids
}

\author{
JEAN LEHMANN \\ Institute for Integrative Biology of the Cell (I2BC), CEA, CNRS, Université Paris-Sud, Campus Paris-Saclay, 91198 Gif-sur-Yvette, France
}

\begin{abstract}
The catalytic site of most enzymes can efficiently handle only one substrate. In contrast, the ribosome is capable of polymerizing at a similar rate at least 20 different kinds of amino acids from aminoacyl-tRNA carriers while using just one catalytic site, the peptidyl-transferase center (PTC). An induced-fit mechanism has been uncovered in the PTC, but a possible connection between this mechanism and the uniform handling of the substrates has not been investigated. We present an analysis of published ribosome structures supporting the hypothesis that the induced fit eliminates unreactive rotamers predominantly populated for some A-site aminoacyl esters before induction. We show that this hypothesis is fully consistent with the wealth of kinetic data obtained with these substrates. Our analysis reveals that induction constrains the amino acids into a reactive conformation in a side-chain independent manner. It allows us to highlight the rationale of the PTC structural organization, which confers to the ribosome the very unusual ability to handle large as well as small substrates.
\end{abstract}

Keywords: ribosome; peptidyl-transferase center; induced fit; aminoacyl-tRNA; EF-P

\section{INTRODUCTION}

An induced fit (or conformational change) has been identified in the peptidyl-transferase center (PTC) of the ribosome, in which the binding of the $3^{\prime}$ acceptor arm of an A-site aminoacyl tRNA triggers a major rearrangement of two ribosome residues, U2506 and U2585 (Escherichia coli numbering throughout this paper) (Schmeing et al. 2005a). The role of this induction in catalysis is, however, not clear. Upon induction, U2585 moves away from the reactive site in a way consistent with the hypothesis that it is protecting the peptidyl tRNA ester bond from premature hydrolysis in the uninduced state (Schmeing et al. 2005a). This interpretation was, however, questioned (Trobro and Aqvist 2006) on the grounds that puromycin $(\mathrm{Pm})$ reacts at a very high rate (Monro and Marcker 1967; Sievers et al. 2004; Schroeder and Wolfenden 2007) despite the fact that this minimal substrate is unable to trigger the PTC conformational change. With Pm as the A-site substrate, the catalytic power of the ribosome has been attributed to an entropy reduction (as compared with a similar reaction in solution) (Sievers et al. 2004; Schroeder and Wolfenden 2007), a phenomenon that was proposed to result from the preorganization within the ribosome of a water molecule stabilizing the transition state

Corresponding author: jean.lehmann@i2bc.paris-saclay.fr Article is online at http://www.rnajournal.org/cgi/doi/10.1261/rna.057273. 116.
(Trobro and Åqvist 2005). This explanation, however, also left the role of the induced fit unclear. In order to establish the thermodynamics and the kinetics of peptide bond formation with full-length substrates, the accommodation step (during which the $3^{\prime}$ acceptor arm of an A-site tRNA moves into the PTC) should in principle be excluded from the chemical step, a difficulty at the origin of some controversy in the literature (Bieling et al. 2006; Johansson et al. 2008, 2011; Ledoux and Uhlenbeck 2008; Wohlgemuth et al. 2008; Rodnina 2013). Experiments with Phe-tRNA ${ }^{\text {Phe }}$ revealed that the thermodynamic parameters are similar to those obtained with Pm despite the inclusion of the accommodation step into the overall peptidyl transfer reaction (Johansson et al. 2008). This is consistent with the fact that the absence of induction is not necessarily critical with Pm. The methyl tyrosine side-chain of this minimal substrate is very similar to that of phenylalanine, an aspect that is central to our analysis. Notwithstanding some uncertainties associated with the accommodation step, key experimental facts have been established: (i) In the early 1970s, Rychlík et al. (1969, 1970) showed that the activity (i.e., the ability to promote peptide transfer) of minimal A-site acceptor substrates in

(C) 2017 Lehmann This article is distributed exclusively by the RNA Society for the first 12 months after the full-issue publication date (see http:// rnajournal.cshlp.org/site/misc/terms.xhtml). After 12 months, it is available under a Creative Commons License (Attribution-NonCommercial 4.0 International), as described at http://creativecommons.org/licenses/by-nc/4.0/. 
the form of $2^{\prime}\left(3^{\prime}\right)$-O-aminoacyladenosine (A-aa) is dependent on the side-chain of the amino acids. The least active acceptor is consistently A-Gly, while A-Phe is always the best acceptor, with an activity comparable to that of Pm. These authors also established that the relative activity of the acceptors is affected by the nature of the donor substrate. (ii) More recent experiments showed that the nature of the C-terminal amino acid of peptidyl-tRNA donors modulates the rate of peptide bond formation when Pm is used as an acceptor substrate (Muto and Ito 2008; Wohlgemuth et al. 2008). (iii) When full-length tRNA are present on both A- and P-sites, the apparent rate of peptide bond formation is approximately independent of the nature of the amino acid at physiological pH (Ledoux and Uhlenbeck 2008; Wohlgemuth et al. 2008; Johansson et al. 2011), with the exception of proline (Pavlov et al. 2009). In addition, some short peptides are known to interfere with the PTC activity owing to their interaction with the exit tunnel (Ramu et al. 2011; Rychkova et al. 2013).

The purpose of this paper is to present a model that accounts for the above experimental facts and fully explains the role of the induced fit of the PTC. Our investigation was motivated by an earlier analysis predicting a significant influence of the amino acids side-chain on the kinetics of peptide bond formation in a context without catalytic site (Lehmann 2000). Because most kinetic studies on the ribosome do not show any substantial side-chain effect in normal conditions, we sought to relate the induced-fit mechanism of the PTC with the ribosome's management of the side-chains, leading to the observed kinetics standardization. A key element of our analysis comes from the observation that while the kinetics of peptide bond formation with minimal A-site substrates is side-chain dependent, their single-nucleotide moiety prevents them from triggering PTC induction. We thus examined the possibility that the structure of the PTC cavity in the uninduced state may accommodate and stabilize unreactive rotamers of A-aa substrates. In the section "Rates of peptide bond formation with minimal A-site substrates," the activity of these minimal substrates is analyzed in terms of reaction rate $\left(k_{\mathrm{cat}}\right)$ and the Michaelis-Menten constant $\left(K_{\mathrm{m}}\right)$. We show that these activities reflect a $k_{\text {cat }}$ dispersion among some of them. Following an overview of structural features characterizing the uninduced and induced states (section "Induced fit of the PTC and nature of the substrates"), we show that the room available inside the PTC cavity and its flexibility in the uninduced state leaves some conformational freedom to the esterified amino acids (section "The uninduced state of the PTC provides some conformational freedom to the aminoacyl esters"). This feature enables the stabilization of rotamers for which the amino group is not oriented for nucleophilic attack, thus explaining why some minimal substrates react poorly. In the section "The induced fit orients the aminoacyl ester for nucleophilic attack," we show that induction corresponds to a compaction of the PTC, which forces any natural L-aminoacyl ester to adopt a unique (reactive) conformation. On the whole, our results allow us to highlight the rationale of the PTC structure-function relationship, this catalytic site having the very unusual requirement to accommodate large as well as small substrates. It appears that the uninduced state is required to let large amino acids enter the catalytic site, in which they are readily positioned for nucleophilic attack, except in specific cases. On the other hand, induction is crucial for orienting some smaller aminoacyl esters, the most critical one being glycine. These conformational effects went unnoticed in many ribosome studies in part because they may not significantly occur with Pm and Phe-tRNA ${ }^{\text {Phe }}$, which are often used as model substrates.

\section{RESULTS}

\section{Rates of peptide bond formation with minimal A-site substrates}

The nature of the side-chain of A-aa acceptor substrates has been shown to strongly affect the acceptor activity in the peptidyl transfer reaction on the ribosome (Fig. 1; Nathans and Neidle 1963; Rychlík et al. 1969, 1970). This activity is furthermore affected by the nature of the P-site donor. The most efficient (A-Phe) and the least active (A-Gly, A-DPhe) acceptors are, however, the same in all three donor configurations so far systematically tested (Rychlík et al. 1970). An analysis of the data of Figure 1 (Supplemental Text S1) reveals that with Lys $(n)$-tRNA on the P-site, A-Phe has a catalytic rate constant $\left(k_{\text {cat }}\right) \sim 50$ to 100 fold higher than A-Gly. APhe has approximately the same acceptor activity as Pm (Nathans and Neidle 1963; Rychlík et al. 1970), for which

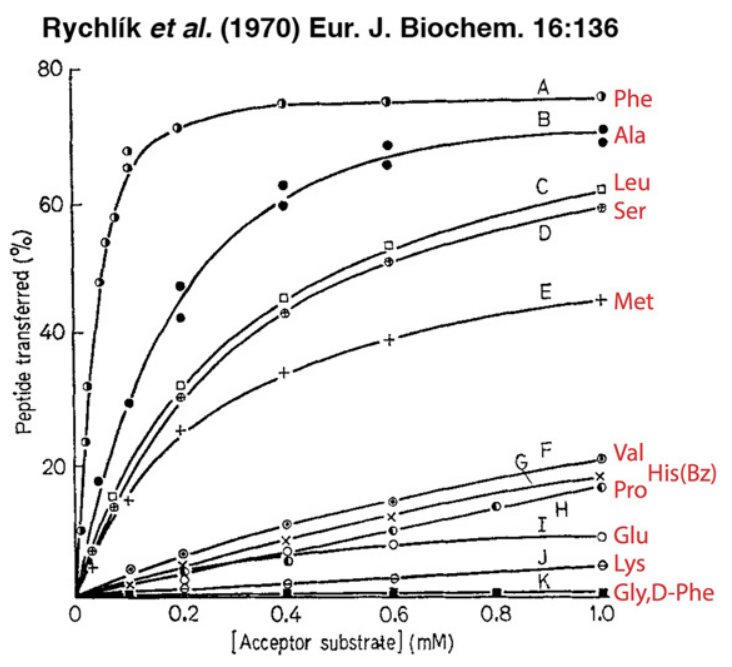

FIGURE 1. Transfer of peptide residues from Lys $(n)$-tRNA $(n=2-7)$ to minimal acceptor substrates in the form of $2^{\prime}\left(3^{\prime}\right)-O$-aminoacyladenosine (A-aa). For each acceptor concentration, the amount of peptide transferred (in percentage) was determined after a 40-min incubation at $35^{\circ} \mathrm{C}$ (see the original publication for details). (Reproduced from Rychlík et al. 1970, with kind permission of John Wiley \& Sons (C) 1970.) 
$k_{\text {cat }}$ has independently been established to $\sim 5 \mathrm{sec}^{-1}$ with MetPhe-tRNA ${ }^{\text {Phe }}$ as the donor substrate, under standard conditions at $25^{\circ} \mathrm{C}$ (Sievers et al. 2004).

In a more recent series of experiments, the influence of various $\mathrm{P}$-site $\mathrm{C}$-terminal amino acids on $k_{\text {cat }}$ was determined at $37^{\circ} \mathrm{C}$ with $\mathrm{Pm}$ as the A-site acceptor (Wohlgemuth et al. 2008). In that case, the amplitude of the side-chain effect is of about one order of magnitude $\left(k_{\mathrm{ca}} \sim 10-100 \mathrm{~s}^{-1}\right)$, with proline as a notable outlier $\left(k_{\text {cat }} \sim 0.1 \mathrm{sec}^{-1}\right)$.

So far, no structural explanation has been proposed for these side-chain effects, observed when the (A-site) acceptor is a minimal substrate ( $\mathrm{Pm}$ or A-aa). They were originally thought to result from various A-site binding propensities (Nathans and Neidle 1963; Rychlík et al. 1970) or from perturbed positioning owing to the small size of these substrates (Wohlgemuth et al. 2008). The most remarkable fact is that they are not observed when A-site and P-site substrates consist of aminoacyl-tRNA and peptidyl-tRNA, respectively (Ledoux and Uhlenbeck 2008; Wohlgemuth et al. 2008; Johansson et al. 2011). At least two sets of data suggest that $k_{\text {cat }}$ standardization occurs with full-length substrates. Ehrenberg and coworkers (Johansson et al. 2008, 2011) established rate constants encompassing the events occurring after the GTP hydrolysis of the ternary complex. Although these constants $\left(k_{\text {pep }}\right)$ comprise tRNA accommodation, the $\mathrm{pH}$ dependences determined with various amino acids are consistent with the established $\mathrm{p} K_{\mathrm{a}}$ values of the amino groups, revealing that the chemical step can be monitored due to a time scale larger than (or comparable to) the time scale of accommodation. These measurements show that only a residual $\sim 3.5$-fold side-chain effect $(\sim 4.5$-fold when proline is included) occurs at $\mathrm{pH} 7.5$ with full-length substrates (Johansson et al. 2011). While the $k_{\text {pep }}$ values for the aminoacyl esters reach their maxima at $\mathrm{pH}$ values that are consistent with the predicted $\mathrm{p} K_{\mathrm{a}} \mathrm{s}$, the highest rate observed (with Phe, $k_{\text {pep }} \sim 25 \mathrm{sec}^{-1}$ at $T=20^{\circ} \mathrm{C}$ ) saturates below $\mathrm{pH} 7.5$, suggesting that this rate could just as well correspond to the time scale of tRNA accommodation. Although this possibility cannot be ruled out, at least one study suggests that a $k_{\text {cat }}$ standardization phenomenon occurs as a result of the interaction of full-length substrates with the PTC. While investigating the effects of the sidechains (at $T=37^{\circ} \mathrm{C}$ and $\mathrm{pH} 7.5$ ), Rodnina and coworkers found that with proline as the C-terminal residue on the $\mathrm{P}$ site, the kinetic constant $\left(k_{\text {cat }}\right)$ established with a saturating concentration of Pm is exceptionally low. Remarkably, the rate constant $k_{\text {app }}$ obtained with Phe-tRNA ${ }^{\text {Phe }}$ under the same conditions is $\sim 50$-fold higher, despite $k_{\text {app }}$ comprising tRNA accommodation (Wohlgemuth et al. 2008). Furthermore, this kinetic constant was found not to depend on the nature of the C-terminal residue. Regardless of the rate-limiting step issue, we will show below that the structural rearrangement resulting from the interaction of fulllength substrates with the PTC is fully consistent with the $k_{\text {cat }}$ standardization hypothesis.

\section{Induced fit of the PTC and nature of the substrates}

An induced-fit mechanism has been identified in the PTC of the ribosome by Steitz and coworkers (Supplemental Fig. S1; Schmeing et al. 2005a). This mechanism could be outlined as follows: Crystal structures show that in the absence of an Asite substrate, or when there is a minimal substrate no larger than CPm (see discussion in Schmeing et al. 2005a, p. 523), the PTC remains in an uninduced state. In this state, U2506 forms a wobble base pair with G2583. At the same time, $\mathrm{U} 2585$ is pointing toward the A-site while being fairly mobile according to molecular dynamic simulations (Trobro and Åqvist 2006). When a minimal substrate is present, its adenosine moiety forms an A-minor interaction with G2583 (Nissen et al. 2001; Bashan et al. 2003; Voorhees et al. 2009) while the $2^{\prime}-\mathrm{OH}$ is hydrogen bonded to $\mathrm{U} 2585(\mathrm{O} 4)$. When the A-site substrate is either CCPm or the $3^{\prime}$ end of a tRNA, the base triplet $\mathrm{C}_{1} \mathrm{C}_{2} \mathrm{Pm}$ or $\mathrm{C}_{74} \mathrm{C}_{75} \mathrm{~A}_{76}$ squeezes in between $\mathrm{U} 2555$ (on which $\mathrm{C}_{1 / 74}$ stacks) and G2583 (with which Pm/ $\mathrm{A}_{76}$ forms an A minor interaction), a configuration stabilized by the $\mathrm{C}_{2 / 75}-\mathrm{G} 2553 \mathrm{WC}$ base pair (Schmeing et al. 2005a; Voorhees et al. 2009). This compression is resolved through the breakage of the G2583-U2506 base pair, triggering U2506 to move to another equilibrium position. In this new configuration, U2506 keeps U2585 away from the reaction center (Supplemental Fig. S1B).

An examination of the two states made us realize that the resolution of the mentioned compression is responsible for a higher compactness of the PTC after induction, a so far unnoticed property that has a strong consequence for the conformational freedom of the esterifier amino acids. A comparison between uninduced and induced states indeed shows that there is more room for the A-site aminoacyl ester in the uninduced state, essentially because U2506 is kept away from the reaction center (Fig. 2).

In the induced state, U2585 is squeezed in between U2584 and U2506, which keeps U2506 in close contact with the Ca atom of the amino acid (Fig. 2B). This configuration locks the amino group at a distance $d \sim 3.18 \AA$ from the carbonyl carbon and at an angle of $\alpha \sim 35^{\circ}$ to the normal of the carbonyl plane in the crystal (as established with pdb 2WDM and $2 \mathrm{WDN})$. It is thus borderline of a near-attack conformation (NAC) (see Materials and Methods), for which $d$ is within 3.2 and $2.8 \AA$ (when the nucleophile is the smaller oxygen) and $\alpha \leq 30^{\circ}$ (Lightstone and Bruice 1994). An uncertainty however remains due to the resolution of the crystal structure $(3.5$ $\AA$ ) and the possible influence of a $\mathrm{O}_{\text {ester }} \rightarrow \mathrm{N}_{\text {amide }}$ substitution. Assuming that confined molecules wedged in a conformation borderline NAC in the crystal fulfill the NAC criteria roughly half of the time (i.e., $p_{\mathrm{NAC}} \sim 0.5$ ), computational work predicts a relative rate constant of the order of $10^{7} \mathrm{M}$ compared with free reactants in solution (Tables 1 and 2 in Lightstone and Bruice 1996). This acceleration compares well to a value determined by thermodynamic measurements (Sievers et al. 2004). 
A

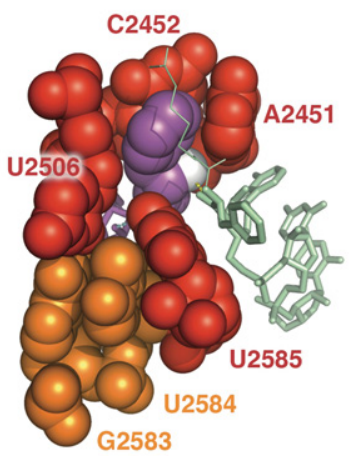

B

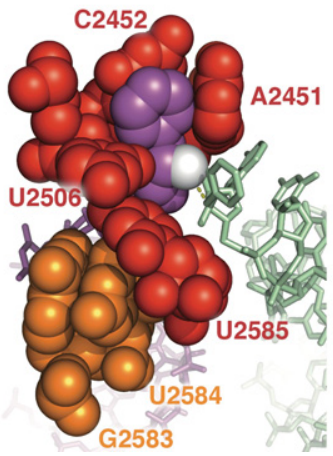

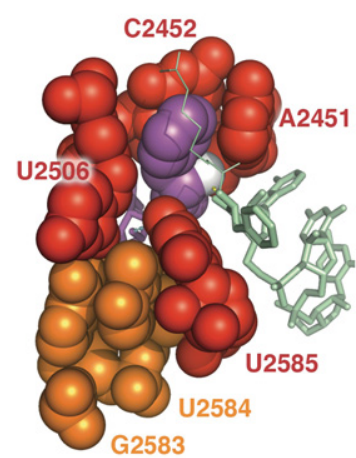

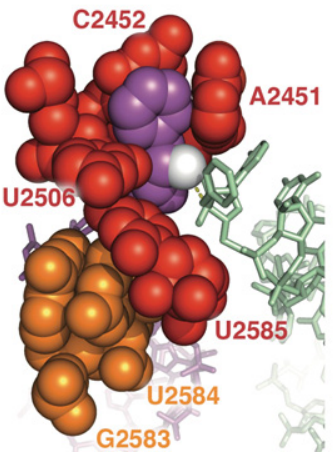

FIGURE 2. Peptidyl-transferase center (PTC) before $(A)$ and after $(B)$ induction (stereo). (A) Uninduced state: When CA-Phe is on the A-site (in purple, aminoacyl ester highlighted with the van der Waals spheres) and CCA-Phe-biotin is on the P-site (in green, stick representation), no induced fit is observed in the crystal (pdb 1VQ6) (Schmeing et al. 2005a). The biotin connector bound to the P-site aminoacyl ester in shown as thin lines. (B) Induced state: When full-length aminoacyl tRNA is on both A-site and P-site, an induced fit is observed in the crystal (pdb 2WDM and 2WDN) (Voorhees et al. 2009). In $A$ and B, A-site $\mathrm{Phe}(\mathrm{N})$ (i.e., the nucleophile) is shown in white.

In the uninduced state (Fig. 2A), the structural environment in the PTC cavity may provide some conformational freedom to the amino group depending on the amino acid side-chain (see the following section).

\section{The uninduced state of the PTC provides some conformational freedom to the aminoacyl esters}

The minimal substrate A-Gly being the poorest acceptor (Fig. 1), was used as a model to explore the possibility of unreactive rotamer(s) in the uninduced PTC cavity. With the 1VQ6 structure as a starting configuration, the A-site $\mathrm{CPm}$ sidechain was removed to get a molecule where the critical moiety is identical to A-Gly (Fig. 3A). Then, a plausible candidate obtained through a $\pi$ rotation of the free end around the $\mathrm{C}$ (carboxyl)-Ca bond ( $\psi$ dihedral angle) was immediately identified (Fig. 3B). This $\psi(\pi)$ rotamer has a total energy $\sim 0.6 \mathrm{kcal} \mathrm{mol}^{-1}$ lower than the initial conformer (both in vacuo energy minimized), and readily fits the PTC cavity without any steric clash. In addition, the $\mathrm{NH}_{2}$ group of this rotamer is positioned for forming a hydrogen bond with

U2585(O4) already in the (non-energy minimized) 1VQ6 structure. In this configuration, U2585(O4) forms a bifurcated hydrogen bond with the 2 '-OH terminal ribose and the $\mathrm{NH}_{2}$ group. An adjustment of the orientation of U2585 was performed to verify that both the distance and angle of the bifurcated interaction could be fully optimized. This was achieved while also replacing the P-site aminoacyl ester of the 1VQ6 structure, which is perturbed by a biotin, with the equivalent (underivatized) fragment of pdb 2WDM (see Materials and Methods section).

Computational work (Sund et al. 2010; Feldblum and Arkin 2014) shows that each hydrogen bond in a bifurcated interaction can typically have an energy of $2-5 \mathrm{kcal} \mathrm{mol}^{-1}$ in solvent-excluded regions, while a relevant configuration involving $\mathrm{U}(\mathrm{O} 4)$ (Sund et al. 2010) suggests that a value of 2 to $2.5 \mathrm{kcal} \mathrm{mol}^{-1}$ is most likely to occur for the additional $\mathrm{U} 2585(\mathrm{O} 4)-\mathrm{A}-\mathrm{Gly}\left(\mathrm{NH}_{2}\right)$ interaction. To establish this, it must be acknowledged that the $\mathrm{NH}_{2}$ group is $>4 \AA$ away from any potential $\mathrm{H}$-acceptor in the initial configuration (Fig. 3A) - the only possible candidate, A2451(N3), has been ruled out by mutational analysis (Erlacher et al. 2005). With a total energy difference of $\sim 2.5$ to $3.0 \mathrm{kcal}$ $\mathrm{mol}^{-1}$, the A-Gly $\psi(\pi)$ rotamer is expected to be $\sim 100$ times more populated than the reactive conformer.

We next investigated the possibility of the A-Phe $\psi(\pi)$ rotamer. A slight rotation of the phenylalanyl moiety around the ester bond was required before energy minimization to avoid a clash with A2451 in the 1VQ6 structure. The rotamer resulting from this operation has a total energy $\sim 1.2 \mathrm{kcal}$ $\mathrm{mol}^{-1}$ lower than the initial conformer. In this situation, an orientation of U2585 corresponding to that of the (induced) $2 \mathrm{WDN}$ structure enables the phenylalanine sidechain to nearly fit this region of the PTC cavity (Fig. 4A). It however does not allow U2585(O4) to hydrogen bond with A-Phe $\left(\mathrm{NH}_{2}\right)$. This orientation of $\mathrm{U} 2585$ is plausible since it is observed in MD simulations even in the absence of strain
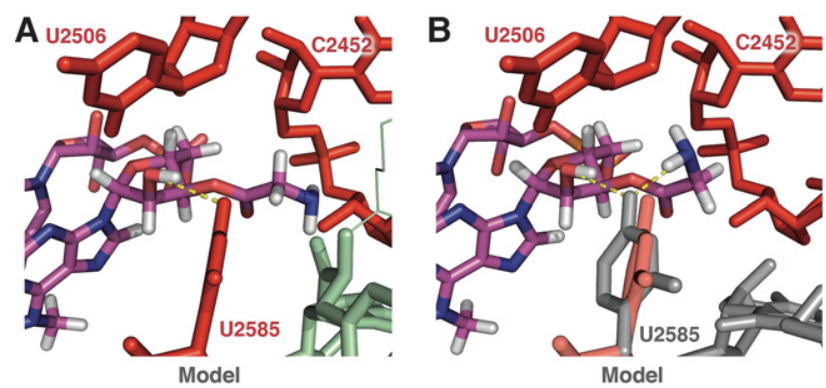

FIGURE 3. Energy minimized A-Gly 5 ' $\mathrm{p}$ fragments aligned in the uninduced PTC cavity (from pdb 1VQ6). (A) Initial conformer derived from the A-Phe 5'p fragment of the 1VQ6 structure. The ribose $\left(2^{\prime}-\mathrm{OH}\right)-$ $\mathrm{U} 2585(\mathrm{O} 4)$ hydrogen bond is shown in yellow. $(B) \psi(\pi)$ rotamer, enabling the additional $\mathrm{Gly}\left(\mathrm{NH}_{2}\right)-\mathrm{U} 2585(\mathrm{O} 4)$ hydrogen bond. The adjusted orientation of U2585 (in gray) results in both hydrogen bonds with a D-A distance of $3.0 \AA$. The P-site A-Phe fragment (in gray) is from pdb 2WDM (see Materials and Methods section). Hydrogens (and atom colors) are only shown on the fragments. 


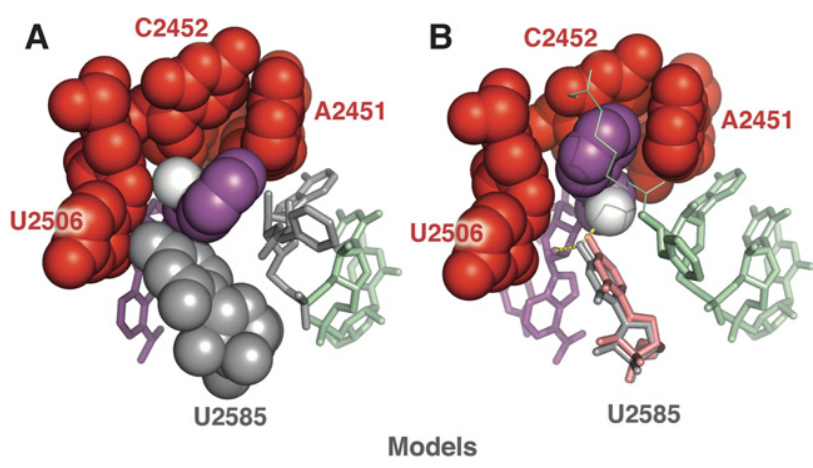

FIGURE 4. (A) Energy minimized $\psi(\pi)$ rotamer of A-Phe 5'p aligned in the uninduced PTC cavity (pdb 1VQ6). This rotamer has a total energy $\sim 1.2 \mathrm{kcal} \mathrm{mol}^{-1}$ lower than the original conformer. Residues in gray are from pdb $2 \mathrm{WDM}$ (P-site A-Phe) and pdb 2WDN (orientation of U2585). (B) A-DPhe 5'p in the uninduced PTC cavity (pdb 1VQ6), built from the original A-Phe 5'p of pdb 1VQ6 (see Materials and Methods section). The position of U2585 (in gray) was slightly shifted from that of the 1VQ6 structure (in pale red) so as to potentially allow a bifurcated hydrogen bond (in yellow). D-A lengths are both $2.9 \AA$; the DHA $\theta$ angle with $\mathrm{Phe}\left(\mathrm{NH}_{2}\right)$ is $\sim 135^{\circ}$. In $A$ and $B$, A-site $\mathrm{Phe}(\mathrm{N})$ is shown in white.

(Trobro and Åqvist 2006). In order to estimate the associated rotameric distribution, a global energy minimization would still be required to resolve tiny residual hydrogen clashes of the A-Phe $\psi(\pi)$ rotamer with A2451. The above analysis with A-Gly and the $\sim 50$ to 100 fold-change in $k_{\text {cat }}$ established between A-Gly and A-Phe (Supplemental Text S1) however suggest that the reactive rotamer of A-Phe (Fig. 2A) could be only slightly more populated than the $\psi(\pi)$ rotamer (Fig. 4A). This $\psi(\pi)$ rotamer is expected to be favored in particular P-site contexts (see below).

It is instructive to confront these structures with the situation provided by the $\mathrm{D}$ enantiomer of A-Phe, for which a very low reactivity was reported (Nathans and Neidle 1963; Rychlík et al. 1970). This molecule is indeed expected to keep its side-chain optimally positioned inside the A2451/ C2452 crevice (Fig. 4B). Similarly to the situation observed with the A-Gly $\psi(\pi)$ rotamer (Fig. 3B), U2585(O4) may also form a bifurcated hydrogen bond, although the $\mathrm{NH}_{2}$ group is less optimally positioned due to a difference of $\sim(\pi / 3)$ in the $\psi$ value. This unreactive configuration was proposed to explain the prevalent exclusion of $\mathrm{D}$-amino acids from translation (Agmon et al. 2004; Zarivach et al. 2004). With D-Pm, peptide incorporation can however be achieved at high concentration (relative to L-Pm) (Starck et al. 2003), indicating that a reactive conformer of this $\mathrm{D}$ enantiomer can fit the uninduced PCT.

Another set of data accounted for by our model is the exceptionally low acceptor activity of Pm observed when the Psite C-terminal donor is proline (Muto and Ito 2008; Wohlgemuth et al. 2008). This configuration was examined while mutating the P-site phenylalanyl ester of Figure 4A to proline. It turns out that the $\psi(\pi)$ rotamer of A-Phe (or $\mathrm{Pm}$ ) enables a $\pi \cdots \mathrm{CH}$ interaction with proline on the P-site
(Supplemental Fig. S2). This type of interaction is strong enough to occur within the aromatic $(n)$-proline $(n+1)$ motif of proteins (Bhattacharyya and Chakrabarti 2003; Zondlo 2013), and is thus expected to stabilize the $\operatorname{Pm} \psi(\pi)$ rotamer in that case. Recent kinetics results obtained with proline derivatives as C-terminal residues and the EF-P cofactor (Doerfel et al. 2015) are analyzed in Supplemental Figure S2. An examination of the structural context shows that geometric constraints prevent the occurrence of similar sidechain-side-chain interactions in the other amino acid configurations tested by Rodnina and coworkers (Wohlgemuth et al. 2008), e.g., Pm-Phe (see Fig. 4A). While an $\sim 60$ - to 700 -fold decrease in $k_{\text {cat }}$ is observed with proline on the $\mathrm{P}$ site (Wohlgemuth et al. 2008), the mentioned $\pi \cdots \mathrm{CH}$ interaction plausibly involves an energy of 1 to $3 \mathrm{kcal} \mathrm{mol}^{-1}$ (Morozov et al. 2004; Jovanovic et al. 2015), compatible with a $>100$-fold change in the affinity ratio required to account for the observed $k_{\text {cat }}$ decrease.

\section{The induced fit orients the aminoacyl ester for nucleophilic attack}

One justification of our hypothesis of unreactive $\psi$ rotamers in the uninduced state is a stabilizing $\mathrm{U} 2585(\mathrm{O} 4)-\mathrm{aa}\left(\mathrm{NH}_{2}\right)$ hydrogen bond (section "The uninduced state of the PTC provides some conformational freedom to the aminoacyl esters"). Induction is precisely removing the possibility of this interaction by moving $\mathrm{U} 2585$ away from the reaction center (Fig. 5A). Furthermore, the $\mathrm{NH}_{2}$ group of any aa-tRNA $\psi$ $(\pi)$ rotamer would clash with $\mathrm{U} 2506(\mathrm{O} 2)$, a destabilizing effect that disappears only with a full switch to the reactive conformation (Fig. 5B). This conformation is maintained because A76 is bound to G2583 while U2584 and U2585 are wedged in between G2583 and U2506, and U2506 is locked in place by G2505 (Fig. 5C). This structural context suggests that the $\mathrm{Ca}$ atom of the aminoacyl ester is held back on the other side by A76 $\left(2^{\prime}-\mathrm{OH}\right)$ of the P-site tRNA, possibly in conjunction with A2451(2'-OH) (Lang et al. 2008). As a logical consequence, the $2^{\prime}$ hydroxyl group of A76 also contributes to orienting the $\mathrm{NH}_{2}$ group toward the carbonyl carbon (Fig. 5B), a possibility in line with the analysis of Green and coworkers (Zaher et al. 2011), and consistent with the significant drop in peptidyl transfer activity observed when this $2^{\prime}$ $\mathrm{OH}$ is replaced with $2^{\prime}-\mathrm{H}$ (Zaher et al. 2011).

The structural hallmark emerging from the above analysis is a mechanism in which $\mathrm{U} 2506(\mathrm{O} 2)$ and $\mathrm{A} 76\left(2^{\prime}-\mathrm{OH}\right)$ are pinching the $\mathrm{C} \alpha$ atom upon induction, an action that orients the aminoacyl ester for nucleophilic attack. It explains the correlation between induced fit and kinetics pointed out previously (Cerná 1975; Quiggle and Chládek 1980; Brunelle et al. 2006). Remarkably, this mechanism preserves a cavity that is optimally positioned for accommodating L-amino acid side-chains (Fig. 5B). Recent experiments with fulllength tRNAs even demonstrate that induction can force the incorporation of several D-amino acids (Fujino et al. 2013). 
A

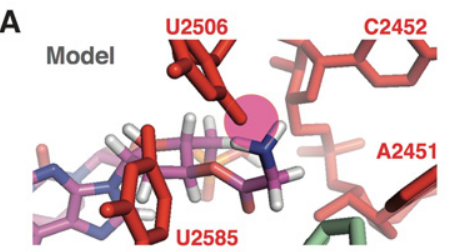

B
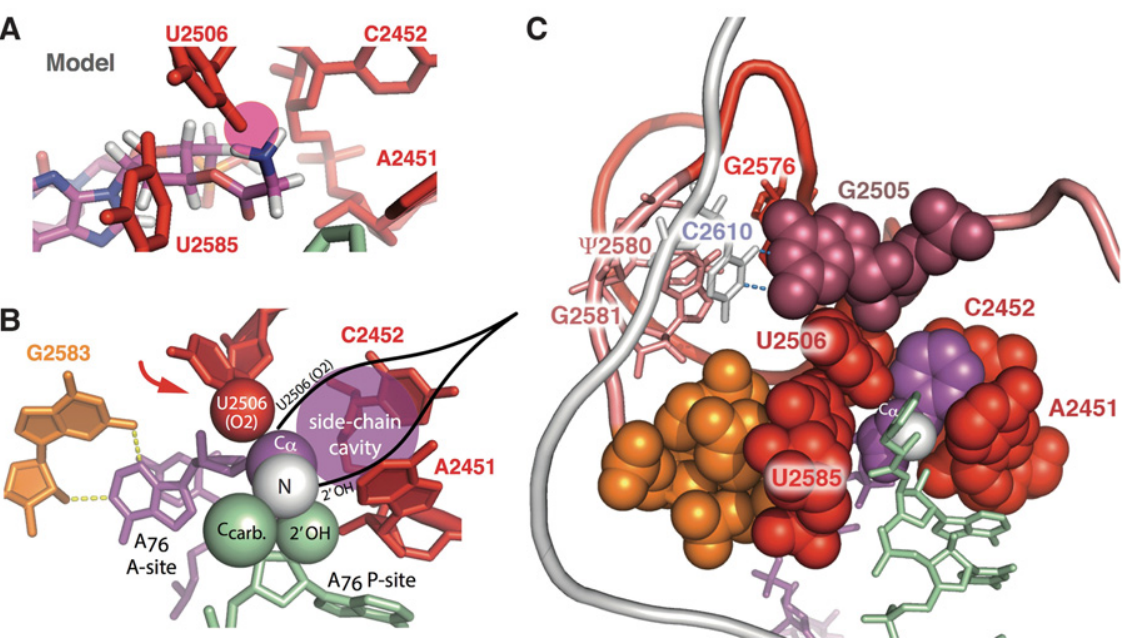

FIGURE 5. Structural constraints resulting from induction. (A) Energy minimized $\psi(\pi)$ rotamer of A-Gly 5'p hypothetically aligned in the PTC cavity in the induced state (pdb 2WDN): A major clash of the amino group with $\mathrm{U} 2506(\mathrm{O} 2)$ (pink circle) prevents this configuration from occurring. (B) View highlighting the U2506(O2)-A76(2'-OH) Ca pinching mechanism enforcing the reactive conformation (the arrow symbolizes the swing of U2506 upon induction). The cavity by the $\mathrm{C} \alpha$ atom accommodates L-amino acid side-chains. Key residues (or only key atoms, highlighted with van der Waals spheres) are shown. A-site aminoacyl tRNA is in purple, with Phe $(\mathrm{N})$ in white; P-site aminoacyl tRNA is in green. $(C)$ Overview of the induced PTC, highlighting ribosomal residues involved in the mechanism orienting the A-site aminoacyl ester by induction. In order for $\mathrm{U} 2506$ to enforce the reactive $\psi$ rotamer through a direct contact with the $\mathrm{Ca}$ atom, this residue must be stabilized in the induced position. The PTC is organized in such a way as to firmly keep the G2505 nucleotide in a stretched orientation that, in conjunction with U2585, holds U2506 in place. The stability of G2505 is achieved through a reversed WC base pair with C2610, which in turn stacks on G2581 and $\Psi 2580$. In addition, G2505 optimally stacks on G2576. (B) and (C) Unmodified pdb 2WDM and 2WDN structures (Voorhees et al. 2009). drolysis as it does in the uninduced state (Schmeing et al. 2005a), a proposal supported by experiments with deacylated tRNA bound to the A-site, shown to promote such hydrolysis (Caskey et al. 1971; Zavialov et al. 2002). Pm and analogs still react in the uninduced state plausibly because U2585 forms a hydrogen bond with $\mathrm{Pm}\left(2^{\prime}-\mathrm{OH}\right)$ (Fig. 2A), thus opening the gate for nucleophilic attack without full induction. This hypothesis is supported by the very low reactivity of the $2^{\prime}$ deoxy ribose analog of A-Phe (Rychlík et al. 1969).

A major role of the uninduced state identified by our study is to allow large amino acids to enter the PTC cavity. Owing to its compactness, an induced PTC would prevent these residues from going inside, a conclusion that can be drawn from the observation that U2506 is literally trapping their side-chain upon induction (Supplemental Fig. S3). Translation inhibition by $\mathrm{Pm}$ analogues with double-ring side-chains (L-Trp and im.-benzyl-L-His derivatives), for which particularly low efficiencies were determined (Harris et al. 1971), suggests that PTC penetration by very large amino acIn particular, the $\mathrm{D}$-enantiomers of amino acids with only one carbon atom in the side-chain (Ala, Ser, and Cys) are all incorporated almost as efficiently as their L-enantiomer counterparts (Fig. 2 in Fujino et al. 2013). Figure 6 suggests the structural origin of this phenomenon: With alanyl-tRNA as the A-site substrate, the $\mathrm{Ca}$ pinching mechanism can orient both L- and D-enantiomers for nucleophilic attack. Although the side-chain of the D-enantiomer is not oriented toward the center of the cavity, it is small enough not to generate significant clashes upon induction. The incorporation of D-amino acids with larger side-chains (see Fujino et al. 2013) depends on whether a (energetically favorable) rotamer of the side-chain can fit the induced cavity.

\section{DISCUSSION}

\section{Rationale of the peptidyl transferase center structure-function organization}

Our analysis points out that the PTC in the uninduced state provides some conformational freedom to the amino acid acceptors that accounts for their various catalytic rate constants in the reaction of peptide bond formation. Why then does the PTC have an uninduced state? An already proposed explanation is that the orientation of U2585 in the induced state may not protect the P-site aminoacyl ester from premature hy- ids may already be a problem in the uninduced state. It contributes to explain why unnatural amino acids are not efficiently incorporated during translation (e.g., Ye et al. 2008; Ieong et al. 2012). This points out another role for the A-site tRNA's 3' acceptor arm binding, that helps push bulky residues inside the PTC cavity, a phenomenon already considered by Warshel and coworkers (Sharma et al. 2005). It also rationalizes the mobility of U2585 observed in MD simulations before induction (Trobro and Åqvist 2006), crucial to the entering of very large amino acids (Supplemental Fig. $\mathrm{S} 3 \mathrm{~A}$ ). A conclusion is that the low activity in peptidyl transfer reaction observed with the minimal form of these substrates (section "Rates of peptide bond formation with minimal Asite substrates") most likely reflects a slow PTC penetration. The maximal activity observed with A-Phe and Pm indicates that these substrates optimally combine PTC penetration/ binding and reactivity inside the cavity (Vanin et al. 1974).

In brief, freezing the esterified amino acids into a reactive conformation by a compaction of the catalytic site requires an uninduced state to let all the aminoacyl esters enter the PTC.

\section{Why does the modern ribosome confine the esterified amino acids?}

Measurements with various full-length aminoacyl-tRNAs indicate that the rate of peptide bond formation is nearly 


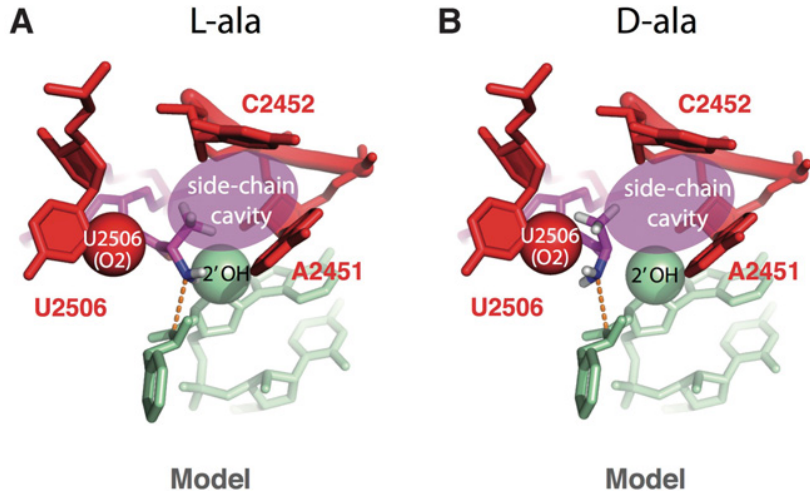

FIGURE 6. PTC in the induced state with (L-alanyl)-tRNA and (D-alanyl)-tRNA as A-site substrates. (A) PTC from pdb 2WDM and 2WDN (Voorhees et al. 2009), with (L-alanyl)-tRNA. The aromatic ring of the original phenylalanine ester (Fig. $2 \mathrm{~B}$ ) was removed to display an alanine side-chain, with no other modification. $(B) \psi$ rotamer of the (D-alanyl)-tRNA counterpart of the structure in $A$. The $\psi$ angle was adjusted so as to obtain a $\mathrm{NH}_{2}-\mathrm{C}$ (carbonyl) distance of $\sim 3.2 \AA$, as in part $A$ (orange dotted lines). In that case, the side-chain does not generate any critical clash with the (non-energy-minimized) PTC structure (max VDW interpenetration $\sim 0.3 \AA$ ), while the angle between the amino group and the normal of the carbonyl plane $(\alpha)$ largely fulfills the $\alpha \leq 30^{\circ}$ requirement for nucleophilic attack. In $A$ and $B$, the two key atoms involved in the $\mathrm{Ca}$ pinching mechanism (see Fig. 5B) are highlighted with van der Waals spheres. Hydrogens are only shown on the $\mathrm{NH}_{2}$ groups and the side-chains.

uniform at physiological $\mathrm{pH}$ (Wohlgemuth et al. 2008; Johansson et al. 2011). An important question is whether this uniformity is due to accommodation being rate-limiting at that $\mathrm{pH}$ or because PTC induction standardizes the kinetic constants of peptide bond formation (these kinetics being heterogeneous with minimal substrates). Let us first consider the issue of PTC induction: Our structural analysis reveals that the induced-fit mechanism constrains $\alpha$-L-aminoacyl esters into a same reactive conformation-provided that full induction can always be reached-(Fig. 5B,C). A significant level of $k_{\text {cat }}$ standardization is thus expected. The connection between conformational freedom and $k_{\text {cat }}$ is further discussed below. Because the amino groups of some aminoacyl esters (Gly, Pro) are characterized by high $\mathrm{p} K_{\mathrm{a}}$ values (Johansson et al. 2011), "full" $k_{\text {cat }}$ standardization could not occur at physiological $\mathrm{pH}$. Considering now tRNA accommodation, kinetic constants comprizing both tRNA accommodation and peptide bond formation span from $k_{\text {pep }}=6.0 \mathrm{sec}^{-1}$ (Pro) to $k_{\text {pep }}=27 \mathrm{sec}^{-1}$ (Phe) at $20^{\circ} \mathrm{C}$ and $\mathrm{pH} 7.5$ (Johansson et al. 2011). Very interestingly, smFRET experiments (at room temperature, $\mathrm{pH}$ 7.5) performed by Blanchard and coworkers show that the average time of tRNA accommodation is $\sim 60 \mathrm{msec}$, i.e., a rate of $15-20$ $\sec ^{-1}$ (Juette et al. 2016 and references therein). Bearing in mind uncertainties and the specificities of both approaches (e.g., the time determined in smFRET experiments includes that of GTP hydrolysis), the comparison of these two results with our structural/kinetics analysis suggests to us that the time scale of tRNA accommodation could in fact just be similar to the time scale of peptide bond formation at physiological $\mathrm{pH}$. This possibility is plausible considering that the whole kinetic scheme of amino acids incorporation likely went through an evolutionary optimization. The physical limit being imposed by the (Brownian-like) accommodation step, no appreciable gain in speed may be obtained with a faster chemical step. The catalytic power of the ribosome is, indeed, not very high compared with that of most enzymes (see the following section).

Returning to the issue of conformational freedom at the PTC, the proper immobilization of the aminoacyl esters by induction is expected to enforce some $k_{\text {cat }}$ standardization with full-length tRNA substrates. Studies on intramolecular reactions have long revealed that the local conformational freedom of a nucleophile has a huge impact on the associated rate constant (Beesley et al. 1915; Bruice and Pandit 1960; Milstien and Cohen 1970; Storm and Koshland 1970; Lightstone and Bruice 1997, 1999; Bruice and Benkovic 2000; Kraut et al. 2003; Garcia-Viloca et al. 2004; Jung and Piizzi 2005). Furthermore, the bulkiness of substituent(s) on the carbon in position 1 or 2 after a nucleophile usually strongly correlates with the reaction rate (Table 1 in Lightstone and Bruice 1996; Tables 1 and 4 in Jung and Piizzi 2005). In the case of $3^{\prime}$ esterified amino acids, we are not aware of any data directly assessing a possible effect of the side-chains on the rate of peptide bond formation in an absence of confinement. However, in the context of a primitive kinetic scheme of translation, a correlation in the genetic code connecting the strength of the anticodon-codon association with the size of the amino acids was interpreted as a consequence of such side-chain effects (Lehmann 2000). Relating anticodon-codon stability to a dissociation rate constant $k$ - and the size of the side-chains to a catalytic rate constant $k_{\text {cat }}$ (large side-chains conferring the highest $k_{\text {cat }}$ ), we interpreted the correlation as a situation for which the equality $k_{\text {cat }} \approx k-$ is verified for each (amino acids|codon) couple (Lehmann 2000; Lehmann et al. 2009), corresponding to an overall optimization of the rate of peptide bond formation on the early ribosome (additional considerations are discussed in Supplemental Fig. S4). The possibility of this kinetic balancing was already suggested as early as 1985 (Remme and Villems 1985). We believe that the side-chain effect is at the origin of the "trick" used by modern ribosomes to freeze any incoming $\alpha$-L-amino acid ester into a same reactive conformation. Because the diversity of side-chains rules out the possibility of their direct interaction with ribosome residue(s), the trick relies on a mechanism pinching the $\mathrm{C} a$ atom of the amino acids while preserving a large cavity capable of accommodating any natural side-chain (Fig. 5B). Another important consequence of the achieved confinement is the significant downshitfs the $\mathrm{p} K_{\mathrm{a}} \mathrm{s}$ of the amino groups resulting from desolvation (Johansson et al. 2011), which makes them more reactive at physiological $\mathrm{pH}$.

Condensing the above information, two proposed reaction paths are shown in Figure 7 (see legend for detailed 
A

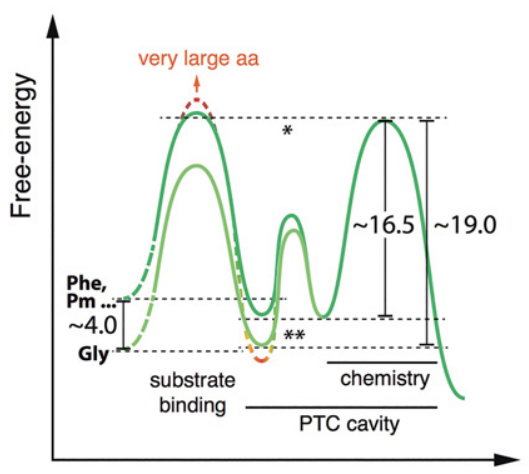

Reaction path
B

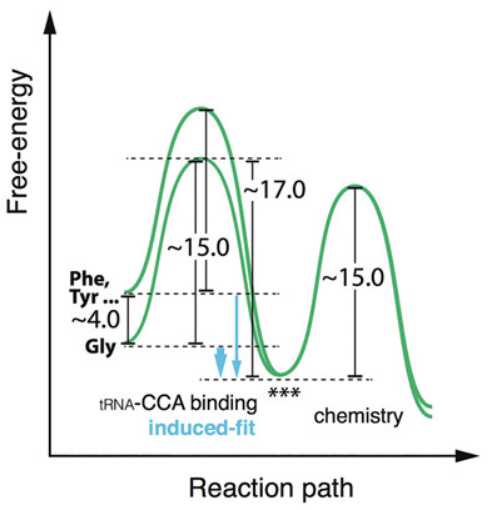

FIGURE 7. Proposed one-dimensional reaction paths on the ribosome with minimal $(A)$ and fulllength $(B)$ A-site substrates. In both cases, a $\sim 4 \mathrm{kcal} \mathrm{mol}^{-1}$ difference at the origin between the least reactive (glycyl) and one of the most reactive (phenylalanyl) aminoacyl ester substrates is inferred from the volume correlation (Supplemental Fig. S4). (A) Minimal substrates (no induction of the PTC). For substrates of a size ranging from A-Gly to A-Phe (or Pm), it is assumed that the association rate constant $k_{\mathrm{on}}$ is approximately uniform. Based on $K_{\mathrm{m}}$ and $K_{\mathrm{d}}$ estimates, we established that $k_{\text {off }} \leq k_{\text {cat }}$ for Pm when Met-Phe-tRNA ${ }^{\text {Phe }}$ is in the P site (*). (Supplemental Text S1). In this configuration, the activation energy of the chemical barrier $\left(\Delta G^{\ddagger}\right)$ is $\sim 16.5 \mathrm{kcal} \mathrm{mol}^{-1}$ at $25^{\circ} \mathrm{C}$ (Sievers et al. 2004). For A-Gly, the stabilization of an unreactive rotamer is predicted to occur upon PTC binding $\left({ }^{* *}\right)$ (Fig. 3), resulting in an overall barrier $\sim 2.5 \mathrm{kcal} \mathrm{mol}^{-1}$ higher (section "The uninduced state of the PTC provides some conformational freedom to the aminoacyl esters"). Aminoacyl esters larger than A-Phe have a higher penetration barrier (arrow, orange dotted line) (see text and Supplemental Fig. S3). Aromatic A-site substrates are predicted to preferentially adopt an unreactive conformation when proline is on the P-site $\left(^{* *}\right.$, orange dotted line) (see section "The uninduced state of the PTC provides some conformational freedom to the aminoacyl esters" and Supplemental Fig. S2). More experiments and MD simulations are required to establish the actual free-energy profiles of reorganization inside the PTC cavity. (B) Full-length substrates (induction of the PTC). The binding of the tRNA $\mathrm{CCA}^{3^{\prime}}$ triplet triggers induction, which forces the backbone of any aminoacyl ester to adopt a same reactive conformation $\left(^{* * *}\right)$ (see Fig. 5B). With essentially preorganized A-site substrates (Phe-tRNA ${ }^{\text {phe }}$ in most P-site contexts), induction leads the system to a lower free-energy level (thin blue arrow) compared to substrates for which reorganization takes a significant amount of free energy (Gly-tRNA ${ }^{\text {gly }}$, thick blue arrow). These free-energy profiles illustrate the hypothesis that the rates of accommodation/binding (defining the height of pre-chemistry barriers) are comparable to the rates of peptide bond formation at $\mathrm{pH} 7.5$ (see text). In this situation, the approximately uniform overall rates $k_{\text {pep }}$ observed at $\mathrm{pH} \geq 7.5$ (for which $\Delta G^{\ddagger}$ is $\sim 15.0 \mathrm{kcal}$ $\mathrm{mol}^{-1}$ at $25^{\circ} \mathrm{C}$ ) (Johansson et al. 2008, 2011; Ledoux and Uhlenbeck 2008; Wohlgemuth et al. 2008) are implemented by setting any prechemistry barrier $\geq 2 \mathrm{kcal} \mathrm{mol}^{-1}$ higher than the chemistry barrier from the bound state $\left({ }^{* * *}\right)$ (i.e., $a \cdot k_{\text {off }} \leq k_{\text {cat }}$ with a somewhat arbitrary $\left.a \sim 10^{1}-10^{2}\right)$. This preliminary proposal is meant to serve as a basis for improvements.

explanations). With minimal substrates (Fig. 7A), the sidechains significantly determine both the kinetics of PTC binding/unbinding and the kinetics of peptide bond formation. Figure 7B represents the situation with full-length tRNA substrates: Following accommodation, the binding of the tRNA $\mathrm{CCA}^{3^{\prime}}$ end triggers the induced fit, which forces the backbone of any natural $\mathrm{L}$-amino acid to adopt a single reactive conformation. For simplicity (and due to lack of information), a single prechemistry barrier is shown that comprizes tRNA accommodation, $\mathrm{CCA}^{3^{\prime}}$ binding (leading to a partial confinement of the aminoacyl ester) and induced fit (achieving full confinement of the aminoacyl ester). The lower chemistry barrier observed with full-length tRNA could be due to the compaction of the active site (Zhang and Klinman 2011).

The hallmark of this proposal (Fig. 7B) is the approximately uniform overall rates, in agreement with experimental data at physiological $\mathrm{pH}$ (Ledoux and Uhlenbeck 2008; Wohlgemuth et al. 2008; Johansson et al. 2011). It suggests an explanation for the size of the fragment of the tRNA acceptor arm that binds at the door of the PTC (the $\mathrm{CCA}^{3^{\prime}}$ triplet). Some of this binding energy is invested in the induced fit, and thus in reorganization (Herschlag 1988; Xiang et al. 2008; Ram Prasad et al. 2012). When no substantial reorganization takes place (Phe-tRNA ${ }^{\text {phe }}$ in most P-site context), the trajectories show that a free energy change of at least $-(4.0+2.0)=-6.0 \mathrm{kcal} \mathrm{mol}^{-1}$ mainly results from acceptor arm binding, an energy that could not be provided by the binding of an RNA fragment shorter than a trinucleotide. Note that the $\Delta G_{0}$ of $-4.0 \mathrm{kcal} \mathrm{mol}$ at the origin is established from an analysis of the early context of translation (Supplemental Fig. S4).

\section{On the entropy of the activation energy of the reaction of peptide bond formation}

A seminal investigation (Sievers et al. 2004; Schroeder and Wolfenden 2007) has shown that the ribosome is essentially reducing the entropy of activation $\left(\Delta S^{\ddagger}\right)$ of peptide bond formation as compared with an "equivalent" reaction in solution, a reduction that accounts for the $\sim 10^{7}$ fold rate enhancement produced by the ribosome (Sievers et al. 2004). An estimate we provide in the "Induced-fit of the PTC and nature of the substrates" section suggests that this effect may entirely result from substrate orientation, a possibility that was already supported (Schroeder and Wolfenden 2007; Moore and Steitz 2011). Substrate orientation is related to the thermodynamic concept of "ground state preorganization" (Storm and Koshland 1970; Lightstone and Bruice 1999; Bruice and Benkovic 2000; Armstrong and Amzel 2003; Kraut et al. 2003; Garcia-Viloca et al. 2004), in which the cost of binding a substrate with an appropriate orientation for nucleophillic attack (an effect that reduces $\Delta S^{\ddagger}$ ) is paid through binding enthalpy.

An alternate (or complementary) possibility, suggested to explain the decrease of $\Delta S^{\ddagger}$ compared with the reaction in solution, is an electrostatic preorganization of the active site (Trobro and Åqvist 2005). It was found in crystals and MD simulations that a water molecule trapped inside the ribosome is plausibly involved in the stabilization of the oxyanion of the 
transition state (Schmeing et al. 2005b; Trobro and Åqvist 2005). An experimental investigation could not, however, support this role for the water molecule, which suggests that the ribosome uses another strategy to stabilize the transition state (Carrasco et al. 2011). It can be mentioned that the two seminal computational studies on the ribosome (Sharma et al. 2005; Trobro and Åqvist 2005) did not agree on the amplitude of the entropic effect associated with catalysis.

Our earlier studies (Lehmann 2000; Lehmann et al. 2009) and the present analysis provide the evidence that, if the ribosome plausibly reduces height of the chemistry barrier compared with a similar reaction in solution, it certainly plays a major role in substrate reorganization through the induced fit of the PTC, an effect that significantly contributes to increasing the kinetic constant of peptide bond formation of most substrates, and ensures a nearly uniform rate of incorporation of the amino acids. Our structural analysis points out that the ribosome architecture responsible for this mechanism (Fig. 5C) is far from being trivial. We believe that the issue of reorganization went partially unnoticed because puromycin, which is used in most experimental studies, is an optimal substrate that does not need to (and cannot) trigger the induced fit to achieve a high rate of incorporation in most P-site contexts.

\section{Conclusion}

The present analysis reveals that the induced fit of the PTC of the ribosome is required for the proper incorporation of all natural $\alpha$-L-amino acids into a nascent protein. Depending on the A-site (aminoacyl) and P-site (C-terminal peptidyl) context, peptide bond formation may be significantly impaired by the occurrence of $\psi$ rotamer(s) of the A-site aminoacyl ester before induction. The concurrent binding of the tRNA's $3^{\prime}$ acceptor arm triggers a compaction around the amino acid that forces it to adopt a reactive conformation. The induced-fit mechanism also prevents a premature hydrolysis during translation, a property identified in the seminal study of Schmeing et al. (2005a). Our results suggest that the rather large size of the ribosome structure around the PTC is due to architectural constraints required to establish a robust induced-fit mechanism. It explains why the ribosome is a "versatile catalyst" (Rodnina 2013), capable of "packing" various substrates provided they can properly undergo induction.

Our analysis, centered on the structure and the origin of the genetic code (Lehmann 2000), predicted that the sidechains of the amino acids contributed to the establishment of the genetic code at the level of the ribosome in the absence of a PTC and a decoding center. In conjunction with optimizations at the level of tRNA (especially at the level of the anticodon loop), both sites have apparently evolved to free translation from basic physicochemical constraints, resulting in a standardization of the rate constants. This normalization was likely a prerequisite to the development of the regulation of gene expression.

\section{MATERIALS AND METHODS}

A semiquantitative assessment of the structures being investigated was performed using the openbabel package, version 2.3.2 (O'Boyle et al. 2011). 3'-O-aminoacyladenosine $5^{\prime}$ phosphate (A-aa 5'p) rotamers were in vacuo energy minimized with the steepest descent algorithm while using the MMFF94 force field. Convergence always occurred within 10,000 steps. Results are expressed in terms of an energy difference between rotamers. A-aa $5^{\prime} \mathrm{p} \psi(\pi)$ rotamers were generated with the "obrotate" tool from the initial molecule of (or derived from) the 1VQ6 pdb file (Schmeing et al. 2005a), and subsequently energy minimized. Refined A-aa 5'p structures were aligned in the PTC cavity using the PyMOL alignment tool. Alignment was solely based on the adenosine moiety of the pdb file. U2585 is known to be a "universally mobile" residue of the PTC (Agmon et al. 2004; Zarivach et al. 2004; Trobro and Aqquist 2006). Depending on the context, the orientation of this nucleotide was adjusted following separately described procedures. Resulting configurations were checked for steric clash; additional energy contributions in the PTC were evaluated separately.

For the configuration with A-site A-Gly 5'p $\psi(\pi)$ rotamer (Fig. $3 \mathrm{~B}$ ), the P-site A-Phe fragment of pdb 2WDM (Voorhees et al. 2009) was aligned to that of pdb 1VQ6 (Schmeing et al. 2005a) solely based on the P-site A76 moiety. The orientation of U2585 was adjusted so as to obtain a bifurcated hydrogen bond in which each bond is characterized by a donor-acceptor (D-A) distance of $3.0 \AA$.

With the (A-site) A-Phe 5'p $\psi(\pi)$ rotamer (Fig. 4A), the P-site APhe fragment of pdb 2WDM has the same alignment as in Figure 3B. The orientation of U2585 was obtained from a PyMOL alignment of the 2580-2590 11-base fragment of 2WDN (Voorhees et al. 2009) (an induced structure) to that of 1VQ6. The A-site D-enantiomer of A-Phe (Fig. 4B) was built with PyMOL from the original A-site L-Phe residue of pdb 1VQ6 with a $\mathrm{NH}_{2} \leftrightarrow \mathrm{H}$ permutation on the $\mathrm{C} \alpha$ atom (a similar procedure was applied on the $2 \mathrm{WDM}$ structure of Fig. 6B). The orientation of U2585 was slightly adjusted so as to position $\mathrm{U} 2585(\mathrm{O} 4)$ in hydrogen bonding distance from Phe $\left(\mathrm{NH}_{2}\right)$ while keeping hydrogen bonding potentiality with A76$2^{\prime} \mathrm{OH}$, with no further optimization.

The Phe-Pro configuration (Supplemental Fig. S2) was derived from Figure 5A. The P-site A-Phe fragment of 2WDM was mutated to A-Pro with the PyMOL mutagenesis tool, and a slight rotation $\left(<5^{\circ}\right)$ of this residue around the ester bond was performed to prevent a steric clash with the A-site side-chain, with no further optimization.

A-site tryptophanyl ester molecules (Supplemental Fig. S3) were obtained with the PyMOL mutagenesis tool from pdb 1VQ6 (uninduced structure) and pdb 2WDM and 2WDN (induced structure). No adjustment of PTC residues was performed.

The near attack conformation (NAC) methodology (Lightstone and Bruice 1994, 1996, 1997) was used to determine whether the conformer of the A-site phenylalanine ester of the (induced) 2WDM and 2WDN structure corresponds to (or is close to) a NAC conformer, i.e. a conformer that can perform nucleophilic attack. It requires the determination of the position of the nucleophile of the A-site phenylalanine ester with respect to the carbonyl carbon of the P-site phenylalanine ester, both in terms of distance to the carbonyl carbon $(d)$ and angle to the normal of the carbonyl plane 
(a). This method has already been used to characterize conformations of reactive species in crystals (Griffin et al. 2012). The determination of $d$ and a was achieved with PyMOL. The equation of the carbonyl plane in the crystal was determined from the $\mathrm{C}$ (carbonyl) and the connected $\mathrm{O}$ and $\mathrm{Ca}$ atoms. It should be mentioned that the NAC analysis has been called into question in cases for which transition state stabilization (TSS) was claimed to better account for the catalytic effect (Strajbl et al. 2003). Furthermore, the NAC analysis does not always provide reliable results (e.g., Garcia-Viloca et al. 2004).

\section{SUPPLEMENTAL MATERIAL}

Supplemental material is available for this article.

\section{ACKNOWLEDGMENTS}

I am very grateful to Daniel Gautheret for supporting my work in his laboratory and for stimulating discussions about many aspects of RNA. I would like to thank François Michel and Benoît Masquida, who examined my analysis in detail and provided many suggestions that improved the manuscript. Several aspects of this work were also improved thanks to comments and suggestions from Shixin Ye-Lehmann, Daniel Gautheret, Fabrice Leclerc, Thomas Simonson, Alexandre V. Morozov, and Pamela Rodriguez. I also would like to thank Pradeep Kumar and Albert Libchaber for inspiring conversations in biological physics and Henri Grosjean for stimulating discussions about tRNA evolution.

Received December 1, 2015; accepted November 18, 2016.

\section{REFERENCES}

Agmon I, Amit M, Auerbach T, Bashan A, Baram D, Bartels H, Berisio R, Greenberg I, Harms J, Hansen HA, et al. 2004. Ribosomal crystallography: a flexible nucleotide anchoring tRNA translocation, facilitates peptide-bond formation, chirality discrimination and antibiotics synergism. FEBS Lett 567: 20-26.

Armstrong AA, Amzel LM. 2003. Role of entropy in increased rates of intramolecular reactions. J Am Chem Soc 125: 14596-14602.

Bashan A, Agmon I, Zarivach R, Schluenzen F, Harms J, Berisio R, Bartels H, Franceschi F, Auerbach T, Hansen HA, et al. 2003. Structural basis of the ribosomal machinery for peptide bond formation, translocation, and nascent chain progression. Mol Cell 11: 91-102.

Beesley RM, Ingold CK, Thorpe JF. 1915. The formation and stability of spiro-compounds. Part I. Spiro-compounds from cyclohexane. J Chem Soc 107: 1080-1106.

Bhattacharyya R, Chakrabarti P. 2003. Stereospecific interactions of proline residues in protein structures and complexes. J Mol Biol 331: 925-940.

Bieling P, Beringer M, Adio S, Rodnina MV. 2006. Peptide bond formation does not involve acid-base catalysis by ribosomal residues. Nat Struct Mol Biol 13: 423-428.

Bruice TC, Benkovic SJ. 2000. Chemical basis for enzyme catalysis. Biochemistry 39: 6267-6274.

Bruice TC, Pandit UK. 1960. The effect of geminal substitution ring size and rotamer distribution on the intramolecular nucleophilic catalysis of the hydrolysis of monophenyl esters of dibasic acids and the solvolysis of the intermediate anhydrides. J Am Chem Soc 82: $5858-5865$.
Brunelle JM, Youngman EM, Sharma D, Green R. 2006. The interaction between C75 of tRNA and the A loop of the ribosome stimulates peptidyl transferase activity. RNA 12: 33-39.

Carrasco N, Hiller DA, Strobel SA. 2011. Minimal transition state charge stabilization of the oxyanion during peptide bond formation by the ribosome. Biochemistry 50: 10491-10498.

Caskey CT, Beaudet AL, Scolnick EM, Rosman M. 1971. Hydrolysis of fMet-tRNA by peptidyl transferase. Proc Natl Acad Sci 68: 3163-3167.

Cerná J. 1975. Effect of cytidine-5'-monophosphate on peptidyl transferase activity. FEBS Lett 58: 94-98.

Doerfel LK, Wohlgemuth I, Kubyshkin V, Starosta AL, Wilson DN, Budisa N, Rodnina MV. 2015. Entropic contribution of elongation factor $\mathrm{P}$ to proline positioning at the catalytic center of the ribosome. J Am Chem Soc 137: 12997-13006.

Erlacher MD, Lang K, Shankaran N, Wotzel B, Hüttenhofer A, Micura R, Mankin AS, Polacek N. 2005. Chemical engineering of the peptidyl transferase center reveals an important role of the 2' -hydroxyl group of A2451. Nucleic Acids Res 33: 1618-1627.

Feldblum ES, Arkin IT. 2014. Strength of a bifurcated H bond. Proc Natl Acad Sci 111: 4084-4090.

Fujino T, Goto Y, Suga H, Murakami H. 2013. Reevaluation of the Damino acid compatibility with the elongation event in translation. J Am Chem Soc 135: 1830-1837.

Garcia-Viloca M, Gao J, Karplus M, Truhlar DG. 2004. How enzymes work: analysis by modern rate theory and computer simulations. Science 303: 186-195.

Griffin JL, Bowler MW, Baxter NJ, Leigh KN, Dannatt HR, Hounslow AM, Blackburn GM, Webster CE, Cliff MJ, Waltho JP. 2012. Near attack conformers dominate $\beta$-phosphoglucomutase complexes where geometry and charge distribution reflect those of substrate. Proc Natl Acad Sci 109: 6910-6915.

Harris RJ, Hanlon JE, Symons RH. 1971. Peptide bond formation on the ribosome. Structural requirements for inhibition of protein synthesis and of release of peptides from peptidyl-tRNA on bacterial and mammalian ribosomes by aminoacyl and nucleotidyl analogues of puromycin. Biochim Biophys Acta 240: 244-262.

Herschlag D. 1988. The role of induced fit and conformational changes of enzymes in specificity and catalysis. Bioorg Chem 16: 62-96.

Ieong KW, Pavlov MY, Kwiatkowski M, Forster AC, Ehrenberg M. 2012. Inefficient delivery but fast peptide bond formation of unnatural Laminoacyl-tRNAs in translation. J Am Chem Soc 134: 17955-17962.

Johansson M, Bouakaz E, Lovmar M, Ehrenberg M. 2008. The kinetics of ribosomal peptidyl transfer revisited. Mol Cell 30: 589-598.

Johansson M, Ieong K-W, Trobro S, Strazewski P, Åqvist J, Pavlov MY, Ehrenberg M. 2011. pH-sensitivity of the ribosomal peptidyl transfer reaction dependent on the identity of the A-site aminoacyl-tRNA. Proc Natl Acad Sci 108: 79-84.

Jovanovic M, Gruden-Pavlovic M, Zlatovic M. 2015. Stabilizing non-covalent interactions of ligand aromatic moieties and proline in ligand-protein systems. Monatsh Chem 146: 389-397.

Juette MF, Terry DS, Wasserman MR, Altman RB, Zhou Z, Zhao H, Blanchard SC. 2016. Single-molecule imaging of non-equilibrium molecular ensembles on the millisecond timescale. Nat Methods 13: $341-344$.

Jung ME, Piizzi G. 2005. Gem-disubstituent effect: theoretical basis and synthetic applications. Chem Rev 105: 1735-1766.

Kraut DA, Carrol KS, Heschlag D. 2003. Challenges in enzyme mechanism and energetics. Annu Rev Biochem 72: 517-571.

Lang K, Erlacher M, Wilson DN, Micura R, Polacek N. 2008. The role of 23S ribosomal RNA residue A2451 in peptide bond synthesis revealed by atomic mutagenesis. Chem Biol 15: 485-492.

Ledoux S, Uhlenbeck OC. 2008. Different aa-tRNA are selected uniformly on the ribosome. Mol Cell 31: 114-123.

Lehmann J. 2000. Physico-chemical constraints connected with the coding properties of the genetic system. J Theor Biol 202: 129-144.

Lehmann J, Cibils M, Libchaber A. 2009. Emergence of a code in the polymerization of amino acids along RNA templates. PLoS One 4: e5773. 
Lightstone FC, Bruice TC. 1994. Geminal-dialkyl substitution, intramolecular reactions, and enzyme efficiency. J Chem Soc 116: 1078910790.

Lightstone FC, Bruice TC. 1996. Ground state conformations and entropic and enthalpic factors in the efficiency of intramolecular and enzymatic reactions. 1. Cyclic anhydride formation by substituted glutarates, succinate, and 3,6-endoxo- $\Delta^{4}$-tetrahydrophthalate monophenyl esters. J Am Chem Soc 118: 2595-2605.

Lightstone FC, Bruice TC. 1997. Separation of ground state and transition state effects in intramolecular and enzymatic reactions. 2. A theoretical study of the formation of transition states in cyclic anhydride formation. J Am Chem Soc 119: 9103-9113.

Lightstone FC, Bruice TC. 1999. Ground state and transition state contributions to the rates of intramolecular and enzymic reactions. Acc Chem Res 32: 127-136.

Milstien S, Cohen LA. 1970. Rate acceleration by stereopopulation control: models for enzyme action. Proc Natl Acad Sci 67: 1143-1147.

Monro RE, Marcker KA. 1967. Ribosome-catalysed reaction of puromycin with a formylmethionine-containing oligonucleotide. J Mol Biol 25: 347-350.

Moore PB, Steitz TA. 2011. The roles of RNA in the synthesis of protein. Cold Spring Harb Perspect Biol 3: a003780.

Morozov AV, Misura KMS, Tsemekhman K, Baker D. 2004. Comparison of quantum mechanics and molecular mechanics dimerization energy landscapes for pairs of ring-containing amino acids in proteins. J Phys Chem B 108: 8489-8496.

Muto H, Ito K. 2008. Peptidyl-prolyl-tRNA at the ribosomal P-site reacts poorly with puromycin. Bioch Biophys Res Commun 366: 1043-1047.

Nathans D, Neidle A. 1963. Structural requirements for puromycin inhibition of protein synthesis. Nature 197: 1076-1077.

Nissen P, Ippolito JA, Ban N, Moore PB, Steitz TA. 2001. RNA tertiary interactions in the large ribosomal subunit: the A-minor motif. Proc Natl Acad Sci 98: 4899-4903.

O'Boyle NM, Banck M, James CA, Morley C, Vandermeersch T, Hutchison GR. 2011. Open Babel: an open chemical toolbox. J Cheminform 3: 33.

Pavlov MY, Watts RE, Tan Z, Cornish VW, Ehrenberg M, Forster AC. 2009. Slow peptide bond formation by proline and other N-alkylamino acids in translation. Proc Natl Acad Sci 106: 50-54.

Quiggle K, Chládek S. 1980. The role of the cytidine residues of the tRNA 3 '-terminus at the peptidyltransferase A- and P-sites. FEBS Lett 118: 172-175.

Ram Prasad B, Kamerlin SCL, Florián J, Warshel A. 2012. Prechemistry barriers and checkpoints do not contribute to fidelity and catalysis as long as they are not rate limiting. Theor Chem Acc 131: 1288.

Ramu H, Vasquez-Laslop N, Klepacki D, Dai Q, Piccirilli J, Micura R, Mankin AS. 2011. Nascent peptide in the ribosome exit tunnel affects functional properties of the A-site of the peptidyl transferase center. Mol Cell 41: 321-330.

Remme J, Villems R. 1985. On the physico-chemical rational of the genetic code. FEBS Lett 189: 159-162.

Rodnina MV. 2013. The ribosome as a versatile catalyst: reactions at the peptidyl transferase center. Curr Opin Struct Biol 23: 595-602.

Rychkova A, Mukherjee S, Bora RP, Warshel A. 2013. Simulating the pulling of stalled elongated peptide from the ribosome by the translocon. Proc Natl Acad Sci 110: 10195-10200.

Rychlík I, Cerná J, Chládek S, Zemlicka J, Haladová Z. 1969. Substrate specificity of ribosomal peptidyl transferase: $2^{\prime}\left(3^{\prime}\right)$-O-aminoacyl nucleosides as acceptors of the peptide chain on the amino acid Site. J Mol Biol 43: 13-24.

Rychlík I, Cerná J, Chládek S, Pulkrábek P, Zemlicka J. 1970. Substrate specificity of ribosomal peptidyl transferase. The effect of the nature of the amino acid side chain on the acceptor activity of $2^{\prime}\left(3^{\prime}\right)$-O-aminoacyladenosines. Eur J Biochem 16: 136-142.

Schmeing TM, Huang KS, Strobel SA, Steitz TA. 2005a. An induced-fit mechanism to promote peptide bond formation and exclude hydrolysis of peptidyl-tRNA. Nature 438: 520-525.

Schmeing TM, Huang KS, Kitchen DE, Strobel SA, Steitz TA. 2005b. Structural insights into the roles of water and the $2^{\prime}$ hydroxyl of the $\mathrm{P}$ site tRNA in the peptidyl transferase reaction. Mol Cell 20: 437-448.

Schroeder GK, Wolfenden R. 2007. The rate enhancement produced by the ribosome: an improved model. Biochemistry 46: 4037-4044.

Sharma PK, Xiang Y, Kato M, Warshel A. 2005. What are the roles of substrate-assisted catalysis and proximity effects in peptide bond formation by the ribosome? Biochemistry 44: 11307-11314.

Sievers A, Beringer M, Rodnina MV, Wolfenden R. 2004. The ribosome as an entropy trap. Proc Natl Acad Sci 101: 7897-7901.

Starck SR, Qi X, Olsen BN, Roberts RW. 2003. The puromycin route to assess stereo and regiochemical constraints on peptide bond formation in eukaryotic ribosomes. J Am Chem Soc 125: 8090-8091.

Storm DR, Koshland DE Jr. 1970. A source for the special catalytic power of enzymes: orbital steering. Proc Natl Acad Sci 66: 445-452.

Strajbl M, Shurki A, Kato M, Warshel A. 2003. Apparent NAC effect in chorismate mutase reflects electrostatic transition state stabilization. J Am Chem Soc 125: 10228-10237.

Sund J, Andér M, Åqvist J. 2010. Principles of stop-codon reading on the ribosome. Nature 465: 947-950.

Trobro S, Åqvist J. 2005. Mechanism of peptide bond synthesis on the ribosome. Proc Natl Acad Sci 102: 12395-12400.

Trobro S, Aqvist J. 2006. Analysis of predictions for the catalytic mechanism of ribosomal peptidyl transfer. Biochemistry 45: 70497056.

Vanin EF, Greenwell P, Symons RH. 1974. Structure-activity relationships of puromycin analogues on Escherichia coli polysomes. FEBS Lett 40: 124-126.

Voorhees RM, Weixlbaumer A, Loakes D, Kelley AC, Ramakrishnan V. 2009. Insights into substrate stabilization from snapshots of the peptidyl transferase center of the intact 70 S ribosome. Nat Struct Mol Biol 16: 528-533.

Wohlgemuth I, Brenner S, Beringer M, Rodnina MV. 2008. Modulation of the rate of peptidyl transfer on the ribosome by the nature of substrates. J Biol Chem 283: 32229-32235.

Xiang Y, Goodman MF, Beard WA, Wilson SH, Warshel A. 2008. Exploring the role of large conformational changes in the fidelity of DNA polymerase $\beta$. Proteins 70: 231-247.

Ye S, Köhrer C, Huber T, Kazmi M, Sachdev P, Yan EC, Bhagat A, RajBhandary UL, Sakmar TP. 2008. Site-specific incorporation of keto amino acids into functional $\mathrm{G}$ protein-coupled receptors using unnatural amino acid mutagenesis. J Biol Chem 283: 1525-1533.

Zaher HS, Shaw JJ, Strobel SA, Green R. 2011. The 2'-OH group of the peptidyl-tRNA stabilizes an active conformation of the ribosomal PTC. EMBO J 30: 2445-2453.

Zarivach R, Bashan A, Berisio R, Harms J, Auerbach T, Schluenzen F, Bartels H, Baram D, Pyetan E, Sittner A, et al. 2004. Functional aspects of ribosomal architecture symmetry, chirality and regulation. $J$ Phys Org Chem 17: 901-912.

Zavialov AV, Mora L, Buckingham RH, Ehrenberg M. 2002. Release of peptide promoted by the GGQ motif of class 1 release factors regulates the GTPase activity of RF3. Mol Cell 10: 789-798.

Zhang J, Klinman JP. 2011. Enzymatic methyl transfer: role of an active site residue in generating active site compaction that correlates with catalytic efficiency. J Am Chem Soc 133: 17134-17137.

Zondlo NJ. 2013. Aromatic-proline interactions: electronically tunable $\mathrm{CH} / \pi$ interactions. Acc Chem Res 46: 1039-1049. 

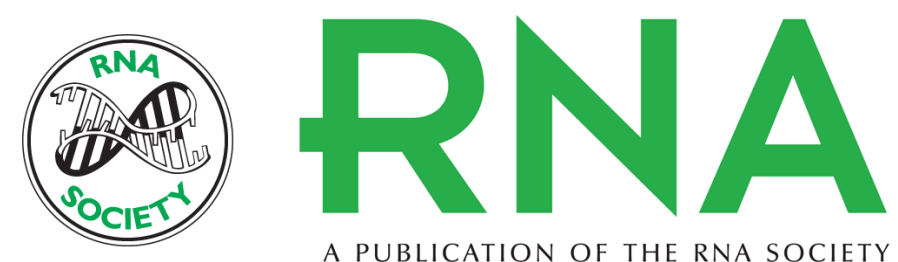

A PUBLICATION OF THE RNA SOCIETY

\section{Induced fit of the peptidyl-transferase center of the ribosome and conformational freedom of the esterified amino acids}

Jean Lehmann

RNA 2017 23: 229-239 originally published online November 22, 2016

Access the most recent version at doi:10.1261/rna.057273.116

\section{Supplemental http://rnajournal.cshlp.org/content/suppl/2016/11/22/rna.057273.116.DC1 \\ Material}

References This article cites 73 articles, 16 of which can be accessed free at: http://rnajournal.cshlp.org/content/23/2/229.full.html\#ref-list-1

Creative This article is distributed exclusively by the RNA Society for the first 12 months after the Commons License full-issue publication date (see http://rnajournal.cshlp.org/site/misc/terms.xhtml). After 12 months, it is available under a Creative Commons License (Attribution-NonCommercial 4.0 International), as described at http://creativecommons.org/licenses/by-nc/4.0/.
Email Alerting Receive free email alerts when new articles cite this article - sign up in the box at the Service top right corner of the article or click here.

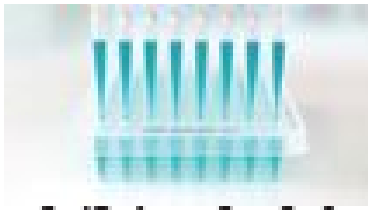

\section{Providing Precise Solutions for} your research.

To subscribe to $R N A$ go to:

http://rnajournal.cshlp.org/subscriptions 